\title{
A construção de projetos didáticos de leitura e escrita como resultado de uma proposta de formação continuada cooperativa
}

\section{Building didactic projects of reading and writing as result of a proposal for cooperative continuing education}

Dorotea Frank Kersch*

Universidade do Vale do Rio dos Sinos

São Leopoldo - Rio Grande do Sul / Brasil

Ana Maria Mattos Guimarães**

Universidade do Vale do Rio dos Sinos

São Leopoldo - Rio Grande do Sul / Brasil

RESUMO: Neste trabalho apresentamos um projeto que se propõe a produzir conhecimento em interação com os professores no processo educativo de leitura e produção escrita do sistema formal de ensino do município de Novo Hamburgo/ RS. Nesse sentido, desenvolve-se um processo de formação continuada cooperativa, em que o letramento acadêmico dos formadores interage com a prática social dos professores e seus alunos, com vistas a propostas didático-pedagógicas que formem um educador apto ao manejo crítico do conhecimento, capaz de estar à frente dos desafios educacionais do terceiro milênio. O processo está respaldado em uma concepção interativa de linguagem, a partir da qual se introduz a noção de gênero, que servirá como âncora para a co-construção de propostas didáticas. $\mathrm{O}$ conceito de sequência didática foi ampliado para colocar a produção de leitura lado a lado com a produção textual e tomá-las como práticas sociais efetivas. Essas características constituem o que estamos chamando de projetos didáticos de gêneros.

PALAVRAS-CHAVE: gêneros; projeto didático; produção escrita; leitura; práticas sociais.

ABSTRACT: In this paper we present a project which aims at knowledge production in interaction with teachers in teaching of reading and writing in state schools in Novo Hamburgo/RS. The proposal includes a collaborative continuing

*doroteafk@unisinos.br

**anag@unisinos.br 
education program, in which the researchers' academic literacies interact with the social practices of teachers and their students, in order to develop didacticpedagogical projects. The goal is to educate teachers to critically engage with knowledge and face the educational challenges of the third millennium. The process is based on an interactive view of language, which introduces the textual genres conception for the co-construction of the teaching activities. The concept of didactic sequence was expanded to incorporate reading together with writing as effective social practices. These features characterize what we are calling genre didactical projects.

KEYWORDS: genres; didactical project; writing production; reading; social practices.

\section{Introdução}

"Lá da Uni vão vir avaliar meu trabalho e dizer que é ruim". Foi como se manifestou um dos professores de nosso grupo de trabalho, de nossa comunidade de indagação (WELLS, 2007), ao refletir sobre sua participação no nosso projeto e manifestar as crenças que alimentava antes de passar a integrar nosso grupo. Esse certamente deve ser o pré-conceito da maioria dos professores quando são convidados a participar de pesquisa em que suas aulas são o foco. Como pesquisadoras (com trajetória anterior na escola básica), questionamo-nos frequentemente: como viabilizar que o que fazemos na academia chegue à sala de aula e dar outro sentido a nossa pesquisa? Como diminuir a já tão propalada distância que separa o fazer da academia do fazer do professor? Como oportunizar que o professor nos veja como parceiras e não como alguém que invade sua privacidade e, de um outro lugar, queira lhe dizer como (não) deve fazer?

O projeto "Por uma formação continuada cooperativa para o desenvolvimento do processo educativo de leitura e produção textual escrita no Ensino Fundamental", sob a coordenação das autoras, conta com o apoio da Capes/ Programa Observatório da Educação, e tem como objetivo aproximar reflexões produzidas/em produção em nível acadêmico ao fazer profissional de docentes de Língua Portuguesa (doravante LP) para, num processo cooperativo, ${ }^{1}$

\footnotetext{
${ }^{1}$ Entendemos como projeto cooperativo aquele que envolve a colaboração dos diferentes atores (no nosso caso, Secretaria de Educação, equipes diretivas das escolas, professores, alunos, pesquisadores, mestrandos e doutorandos, bolsistas de iniciação científica). Num projeto dessa natureza, a todos é permitida uma atitude responsiva ativa, de dialogismo como o princípio que constitui a linguagem e a condição de sentido no discurso (Ver Valentin Voloshinov e Mikhail Bakhtin, citados a seguir).
} 
alavancar o desempenho dos alunos no que diz respeito à leitura e escrita como práticas sociais, vistas como pilares de uma educação preocupada com os desafios do futuro que os espera. No desenvolvimento do projeto, há dois parceiros comprometidos com concepções de educação, mais especificamente de ensinoaprendizagem de língua: o Programa de Pós-Graduação Linguística Aplicada (PPGLA), da Unisinos, e a Secretaria Municipal de Educação (SMED) de Novo Hamburgo, Rio Grande do Sul.

Para vencer as barreiras que imaginávamos existir, propusemos um processo de formação continuada cooperativa, em que o letramento acadêmico dos formadores interagisse com as práticas sociais dos professores e seus alunos. A ideia era (e continua sendo), junto com nossos colaboradores, desenvolver propostas didático-pedagógicas que formem um educador apto ao manejo crítico do conhecimento, capaz de estar à frente dos desafios educacionais do terceiro milênio. Ao final de quatro anos, espera-se que cerca de cem professores de LP da Educação Básica e vinte pós-graduandos estejam em ação na sala de aula com práticas renovadas e voltadas para a construção de objetos de ensino relacionados à leitura e produção textual e, com isso, contribuir para o crescimento dos índices oficiais do município.

Respaldadas em uma concepção interativa de linguagem (BAKHTIN [2003]; BRONCKART [2004]), iniciamos com a discussão de conceitos basilares para um processo dessa natureza: concepção de linguagem, letramento, educação linguística e a noção de gênero, que serve como âncora para a co-construção do que estamos denominando projeto didático de gênero (PDG), como caracterizaremos adiante. Nesses projetos idealizados pelos professores, a partir de marcos conceituais com eles discutidos, o foco principal é a língua escrita, que, a nosso ver, é o principal objetivo da escolaridade.

Tendo como ponto de partida o trabalho desenvolvido pela equipe de Didática de Línguas da Universidade de Genebra e já bastante conhecido no Brasil, a partir do princípio de que "é através dos gêneros que as práticas de linguagem materializam-se nas atividades dos aprendizes" (SCHNEUWLY; DOLZ, 2004, p. 15), procuramos ampliar o conceito de sequência didática, no sentido de colocar a produção de leitura lado a lado com a produção textual, entendendo-as dentro da perspectiva dos estudos de letramento: como práticas sociais que emergem de outras práticas da comunidade em que os alunos estão inseridos (BARTON; HAMILTON [1998]; KLEIMAN [1995], [2008]; OLIVEIRA [2010]). Diferentemente do proposto pelo grupo de Genebra, procuramos atribuir ao processo de leitura a mesma importância do processo de produção textual, dando um detalhamento semelhante. Os módulos ou 
oficinas pensadas para cada projeto pedagógico proposto trazem atividades de leitura que encaminham a produção textual. Daí a ideia de usar, na presente proposta, a noção de PDG como um guarda-chuva para, a partir de uma escolha temática, trabalhar-se um ou mais gêneros em um dado espaço de tempo (um bimestre, por exemplo), sempre com a preocupação de relacionar a proposta a uma dada prática social.

O trabalho proposto recebeu influência também dos chamados projetos de letramento (KLEIMAN [2000]; TINOCO [2009]), entendidos como "práticas de letramento que decorrem de um interesse real na vida dos alunos, servindo para atingir algum outro fim que vai além da mera aprendizagem da língua, no seu aspecto formal" (KLEIMAN, 2000, p. 238). Nesses projetos, não há foco em um ou dois gêneros e, sim, em tantos quantos forem necessários para dar conta da demanda surgida na vida de alunos e professores. O grupo coordenado por Ângela Kleiman tem uma produção expressiva e, sem dúvida, tem trazido contribuiçóes significativas para os estudos de letramento.

O que apresentamos aqui dá conta dos passos iniciais da proposta de formação continuada cooperativa, que tem como base a noção de PDG. O texto está organizado da seguinte forma: apresentação dos pressupostos teóricos que alicerçam nosso trabalho, nossa metodologia de trabalho e os primeiros resultados alcançados.

\section{Os alicerces da proposta}

A introdução do trabalho com gêneros como fio condutor da proposta de ensino-aprendizagem de LP foi oficializada ainda em 1998, através dos Parâmetros Curriculares Nacionais (BRASIL, 1998), mas sabemos que não se pode falar que a proposta tenha avançado a ponto de se tornar uma realidade nas escolas brasileiras. Ainda que a temática esteja sendo desenvolvida por muitos pesquisadores, eles não têm conseguido que os resultados de suas reflexôes cheguem à sala de aula (GUIMARÃES [2006]; BUNZEN [2006]; ANTUNES [2009]; ROJO [2009], só para citar alguns), ou talvez não tenham sido compreendidos, uma vez que as mudanças que se verificam são ainda bastante incipientes. Certamente a maior parte dos professores brasileiros não seria capaz ainda de responder qual a diferença de trabalhar com gêneros ou com textos. ${ }^{2}$ Também, para a grande maioria dos

\footnotetext{
${ }^{2}$ Pelo menos é o que verificamos nos contatos que temos tido com professores da rede pública e privada do Rio Grande do Sul.
} 
professores com quem temos trabalhado, gênero se confunde com tipo textual. $\mathrm{E}$, enquanto isso, o ensino de LP ainda se preocupa muito mais com questôes gramaticais do que com o ler e escrever (GUIMARÃES [2008]; CAMPANI [2008]; DREY [2008]; KERSCH; FRANK [2009], por exemplo).

Não vamos analisar a(s) razão(ões), pois são múltiplas, e de várias ordens, porém, partindo do pressuposto de que a proposta de trabalho com gêneros é importante como foco do ensino de LP, desde que não desvinculada das práticas sociais da comunidade a que os alunos se acham vinculados, optamos por fazer o nosso papel de linguistas aplicadas e nos propomos a investir numa proposta de didática de gêneros. Entendemos que, para atender ao desafio de melhorar índices de um município, é preciso articular as reflexōes acadêmicas com a prática profissional e, para isso, antes de tudo, devem-se conhecer as necessidades do professor (e ele, as dos alunos). A partir disso, é necessária a articulação, desde o início da formação continuada, entre as teorias estudadas e a prática docente, devidamente acompanhada pelos formadores, uma vez que a mudança só se dará a partir do engajamento dos professores. Seguimos o argumento de Dolz (2009) de que a teoria pode enriquecer-se com a prática, podendo até reformular-se, porque, para nós, teoria e prática podem e devem alimentar-se.

$\mathrm{Na}$ sequência, retomamos alguns conceitos-chave que situam este trabalho.

\subsection{Concepção de leitura (e escrita)}

Retomamos parte de recente publicação de Guimarães (2010), que propóe como partida o ponto de vista da concepção de leitura adotado. Pensamos leitura (e, por extensão, também a escrita) como interação, como diálogo entre sujeitos historicamente construídos, de forma a atribuir sentidos; nessa perspectiva, a interpretação ou compreensão do texto do outro é uma forma de diálogo (BAKHTIN [1929]; VOLOSHINOV [2006]; BAKHTIN [2003]). A leitura se configura também como uma forma de entender a possibilidade pedagógica da co-construção de saberes, a partir do diálogo que se estabelece entre os sentidos atribuídos ao texto por seu autor e aqueles dados pelo seu leitor, por sua vez, transformado em autor, numa cadeia que se prolonga. Retomamos Voloshinov e Bakhtin, sobretudo quando pensamos em suas reflexões sobre o princípio dialógico, que anteciparam e muito influenciaram os estudos sobre texto e discurso que conhecemos. Voloshinov, em Marxismo e filosofia da linguagem, sublinha o caráter fundamentalmente social da enunciação e do dialogismo que nela se manifesta. 
Este é nosso ponto de partida: o caráter social dos atos de linguagem que implica a ideia da compreensão como um diálogo, no qual os sentidos são firmados, reafirmados, contrapostos, desmentidos. Em outras palavras, esses sentidos são co-construídos entre os interlocutores. É a partir dessa abordagem do dialogismo, como princípio constitutivo da linguagem, que se desenvolve o tema da atitude responsiva ativa. Bakhtin (2003) retoma essa questão quando afirma que a compreensão gera o pensamento em outro contexto e leva à recriação do objetivo compreendido; essa recriação, por sua vez, altera o sentido do objeto. Assim, para ele, compreender é re-pensar, re-alocar a atividade-alvo sobre a qual se está refletindo.

A vida, para Bakhtin, é dialógica por natureza, sendo o dialogismo o princípio que constitui a linguagem e a condição de sentido no discurso. Assim sendo, a leitura de um texto se estabelece como um processo de construção de sentidos - dialógico -, portanto, como mostra em Estética da criação verbal:

Até hoje existem na lingüística ficções como o "ouvinte" e o "entendedor" (parceiros do "falante", do "fluxo único da fala" etc.). Tais ficçôes dão uma noção absolutamente deturpada do processo complexo e amplamente ativo da comunicação discursiva. [...] Toda compreensão da fala viva, do enunciado vivo é de natureza ativamente responsiva (embora o grau desse ativismo seja bastante diverso); toda compreensão é prenhe de resposta, e nessa ou naquela forma a gera obrigatoriamente: o ouvinte se torna falante. A compreensão passiva do significado do discurso ouvido é apenas um momento abstrato da compreensão ativamente responsiva real e plena... Tudo o que aqui dissemos refere-se, mutatis mutante, ao discurso escrito e ao lido.

Portanto, toda compreensão plena real é ativamente responsiva e não é senão uma fase inicial preparatória da resposta (seja qual for a forma que ela se dê). (BAKHTIN, 2003, p. 271).

O sentido de uma enunciação, portanto, é co-construído: ele não se encontra no indivíduo, no signo linguístico ou no interlocutor, mas na interação entre locutor e interlocutor, mediada pelos signos linguísticos. A noção de compreensão ativa é ilustrativa do movimento dialógico da enunciação. Um locutor, ao propor um enunciado, pressupõe um interlocutor (real ou virtual), do qual requer uma atitude responsiva. A compreensão desse enunciado, por sua vez, não significa simplesmente reconhecer a forma linguística, mas traz junto uma relação entre os significados das palavras empregadas e seu conteúdo ideológico, o que implica considerar as condições de produção e da interação locutor/interlocutor. Ou seja, há uma ação histórica 
compartilhada socialmente, realizada em um tempo elugar específicos, mas mutável, dependendo das variaçôes do contexto. Portanto, pensar no movimento dialógico da enunciação significa enfatizar a natureza contextual da interação e o aspecto sociocultural dos contextos nos quais as interaçóes se realizam.

Dentro dessa perspectiva de dialogismo é que se podem entender "os enunciados e seus tipos, isto é, os gêneros discursivos" ("as correias de transmissão entre a história da sociedade e a história da linguagem") (BAKHTIN, 2003, p. 268), reconhecidos socialmente como manifestações de práticas sociais, cultural e historicamente situadas.

Essa concepção de dialogismo que usamos para fundamentar a concepção-base de leitura do nosso trabalho alicerça-se numa perspectiva sociointeracional de linguagem, ou seja, por acreditar, como Carlos Franchi, que é

[...] na interação social, condição de desenvolvimento da linguagem, que o sujeito se apropria do sistema lingüístico, no sentido que constrói, com os outros, os objetos linguísticos de que vai se utilizar, na medida em que constitui a si próprio como locutor e aos outros como interlocutores. (FRANCHI, 1987, p. 7).

Adotamos, pois, uma abordagem linguística centrada na interação, em que enunciado e discurso pressupõem a troca entre os sujeitos no processo de comunicação (nunca isoladamente, sempre em interação com o outro, que se coloca, a cada ato comunicativo, em postura ativa de resposta). Nesse sentido, pode-se dizer que os gêneros não são adquiridos em manuais, mas nos processos interativos, nas práticas sociais, em eventos de letramento. E é disso que tratamos na sequência.

\subsection{Gêneros e letramento}

Entendemos que o estudo das atividades de linguagem é feito através dos textos (orais e escritos) que as materializam. Tais textos são considerados unidades comunicativas globais e se agrupam em gêneros, "que são socialmente indexados, quer dizer, que são reconhecidos como pertinentes e/ou adaptados para uma situação comunicativa dada" (BRONCKART, 2004, p. 115). Ao entender-se que todo agir linguageiro se configura num texto pertencente a um determinado gênero, valida-se a importância do ensino através de gêneros.

Se, por meio do trabalho com gêneros, queremos contribuir para o letramento dos alunos, assumimos, tal como Gordon Wells (2007) e Bernard 
Schneuwly e Joaquim Dolz (2004), que a melhor maneira de ajudar os alunos a ler e a escrever é criar situações em que tenham de ler e escrever para propósitos específicos (ver, por exemplo, GUIMARÃES [2006]; TINOCO [2009]; KERSCH [2011]). Ou seja, a proposta de ensino deve ser organizada de tal forma que leitura e escrita sejam necessárias para algo. Nesse ponto, os estudos de letramento nos auxiliam a dar outro caráter ao trabalho com gêneros na escola. Se as sequências didáticas (SD), tais como propostas por Schneuwly e Dolz (2004) aparecem como que recortadas da realidade, pensa-se em projetos de gêneros que emerjam dessa realidade. Hoje se sabe que não basta à escola ensinar seus alunos a ler e a escrever, mas cabe a ela criar as condiçôes para que eles desenvolvam suas habilidades de leitura e escrita, em situações muito próximas ao que se faz na vida real, porque letrar não é apenas ensinar a ler e a escrever para a escola, mas capacitar o aluno a agir em todas as instâncias, dentro e fora da escola, nas práticas exigidas pela sociedade. A complexidade do mundo letrado exige também conceitos complexos para entender seus aspectos mais relevantes, e o conceito de letramento auxilia a compreender o impacto da escrita em todas as esferas da vida nessa sociedade (KLEIMAN, 2005).

Ainda que o conceito de letramento venha sendo amplamente discutido na produção científica, nos eventos nacionais e internacionais (tanto na área da Linguística quanto da Educação), esteja presente nos documentos oficiais, e até mesmo seja tema de programa especial do MEC (o Pró-Letramento Mobilização pela Qualidade da Educação, destinado à formação continuada de professores das séries iniciais do ensino fundamental), a exemplo da noção de gênero, também ele não se pode dizer que esteja incorporado à prática docente.

Os estudos de letramento "partem de uma concepção de leitura e de escrita como práticas discursivas, com múltiplas funçōes, e inseparáveis dos contextos em que se desenvolvem" (KLEIMAN, 2007, p. 4), e essas práticas exigem a mobilização de diversos recursos e conhecimentos por parte dos participantes das atividades. Nesse sentido, o aluno precisa se familiarizar com os textos dos diferentes agrupamentos de gêneros, ${ }^{3}$ o que implica oferecer eventos de letramento destinados a promover essa familiaridade.

\footnotetext{
${ }^{3}$ Justamente porque as atividades de sala de aula se organizam em torno dos gêneros, há que se pensar na progressão curricular, distribuindo a variedade de gêneros ao longo dos diferentes níveis de ensino. Essa será uma proposta a ser discutida pelo grupo de pesquisadores/professores bolsistas na próxima etapa do projeto.
} 
O letramento abarca as práticas relacionadas com a escrita em toda a atividade da vida social. Essas práticas estão ligadas a diferentes domínios (lar, escola, igreja, trabalho, rua, vizinhança, comércio, órgãos oficiais etc.), a aspectos específicos da cultura e a diferentes sistemas simbólicos e de circulação (letramento virtual, musical, cinematográfico etc.). Em função disso, há diferentes orientações de letramento; por isso, tal como Brian Street (1984), reconhecemos a existência de uma multiplicidade de letramentos. Ou, como afirma Magda Soares,

diferentes tecnologias de escrita geram diferentes estados ou condiçóes naqueles que fazem uso dessas tecnologias, em suas práticas de leitura e de escrita: diferentes espaços de escrita e diferentes mecanismos de produção, reprodução e difusão da escrita resultam em diferentes letramentos. (SOARES, 2002, p. 156).

O conceito de letramento, portanto, abre espaço para uma nova forma de conceber a relação entre o oral e o escrito. Ao oferecer eventos que envolvem a escrita, inserindo os alunos nas práticas letradas da sociedade, a escola estará levando-os a se comunicarem por escrito numa gama variada de situações. Escrevendo para um fim específico, os alunos estarão motivados a fazer aquilo que não é imediatamente aplicável, mas socialmente relevante e que, portanto, vale a pena ser aprendido.

Os documentos oficiais (PCN e Referenciais, ${ }^{4}$ por exemplo) recomendam, em relação ao ensino de LP, que o aluno seja inserido efetivamente no mundo da escrita e que suas possibilidades de participação social no exercício da cidadania sejam ampliadas. Isso, no nosso entender, acontecerá se ele for envolvido em situações linguisticamente significativas. Nesse sentido, parece que o aluno terá melhor desempenho se for convidado a se engajar num projeto que seja seu, com o qual se identifique e que esteja ligado à cultura da comunidade de que faz parte (por isso a necessidade de o projeto ser coconstruído). Se entendemos que o letramento envolve as "práticas discursivas que precisam da escrita para torná-las significativas, ainda que às vezes não envolvam as atividades específicas de ler e escrever" (BRASIL, 1998, p. 19), vemos que a sala de aula precisa dar conta da complexidade da comunicação contemporânea, o que nos faz assumir, como dissemos acima, a existência de

\footnotetext{
${ }^{4}$ Referenciais Curriculares do Rio Grande do Sul. (RIO GRANDE DO SUL, 2009).
} 
uma multiplicidade de letramentos - associados a diferentes pessoalidades e identidades - que variam no tempo, no espaço e estão ligados a relações de poder. Isso também nos faz pensar que quanto menor for o grau de letramento das comunidades nas quais os alunos se inserem, maior será a responsabilidade da instituição de ensino e dos professores para inseri-los e fazê-los transitar num mundo diferente do seu. Esse entendimento leva à complexidade da atividade docente, especificamente do docente envolvido com a língua materna, assunto de que nos ocuparemos na seção seguinte.

\subsection{A atividade do docente de língua materna}

O docente envolvido com a língua materna está permanentemente diante do desafio de criação e adaptação de dispositivos de ensino. Assim, a profissionalização de um docente supõe a superação da simples colocação em prática dos materiais e técnicas didáticas disponíveis, passando para um outro patamar, que implica desenvolver capacidades de adaptação e criação de novos dispositivos didáticos. Esse, em nosso entender, deve ser o foco de uma proposta de educação continuada para docentes em ação.

Ao mesmo tempo, ratifica-se a necessidade de uma (re)valorização da profissão docente para que haja melhorias na qualidade e eficácia das estratégias e propostas de formação, pois o ensino é um ofício tão profissional quanto qualquer outro. Isso implica, quebrando um paradigma sociocultural tradicional bastante difundido ainda hoje, que ser professor não é um dom, ou sacerdócio; é uma profissão, um trabalho cujos trabalhadores devem se apropriar do conhecimento e das ações necessárias para realizarem seu ofício, adquirindo experiência no desempenho do mesmo para que se tornem, cada vez mais, profissionais, literalmente.

Assim, nessa perspectiva de estudo da questão da formação continuada docente, a análise de práticas de professores, de seus objetos de ensino e dos seus gestos profissionais constituem pontos que podem orientar mudanças no ensino a partir do trabalho do professor. Ao mesmo tempo, entretanto, precisamos colocar em sala de aula uma proposta que permita que objetos de ensino relacionados à leitura e à produção textual constituam verdadeiramente o cerne de um programa de Educação Básica, tomado na transversalidade disciplinar. Torna-se, então, necessário fundamentar e colocar em prática um programa de educação continuada para professores na rede. O projeto é estendido, pois, da ponta de formação à ponta da profissionalização, como uma ponte entre dois mundos: o acadêmico e o da práxis. 
É necessário entender ainda que se parte de um enfoque do interacionismo social, de orientação vygotskiana (VYGOTSKY [1989]; DONATO [1994]; SCHNEUWLY; DOLZ [2004]), que coloca o aprendiz no centro do processo de ensino-aprendizagem. Dessa forma, cada aluno tornase o principal agente de seu aprendizado. Isso afeta fortemente o papel do professor, que passa a ser visto como um mediador entre o que o aluno atualmente detém do conhecimento e o que deve ser desenvolvido. Esse novo papel necessita ser compartilhado, de forma cooperativa, entre os diversos docentes de uma classe. E, para isso, é preciso que o professor reveja seu papel, o que justifica o acompanhamento de uma formação continuada que o situe no centro do processo, da mesma forma que deve passar a fazer com seu aluno. Isso acaba afetando também o formador na universidade, que, ao colocar o professor no centro e buscar com ele as respostas, percebe-se como mediador e não como alguém de quem venha a solução.

\section{A metodologia empregada}

A pesquisa se caracteriza como pesquisa-ação, que entendemos colaborativa. Apoiadas em Wells (2007), consideramos que a pesquisa colaborativa é o modo adequado de conduzir nossa investigação, porque pretendemos substituir a relação hierárquica e assimétrica entre quem faz pesquisa e quem a aplica (ou de quem se espera que a aplique), por uma relação de colaboração no contexto de sala de aula (e fora dela) entre pesquisador e professor. Esse espaço de construção conjunto possibilita vivenciar o que o autor denomina de comunidade de indagação (WELLS, 2006). Para o autor, pensar a comunidade de indagação significa problematizar a prática escolar e refletir sobre ela. Nesse sentido, o professor que se propõe a refletir sobre sua prática e a investigar os processos de construção do conhecimento dos seus alunos (e o seu próprio) vai descobrindo novas possibilidades e significados naquilo em que faz/pensa, o que permite que vá se tornando também ele um(a) pesquisador(a), o que, em nosso entender, é uma característica inerente à prática docente.

$\mathrm{O}$ trabalho aqui relatado refere-se à pesquisa ainda em fase inicial realizada em dois momentos, ${ }^{5}$ cada um com diferentes atores: a comunidade de indagação, e as comunidades de aprendizagem a que ainda queremos chegar,

\footnotetext{
${ }^{5}$ Inicialmente, fez-se a formação dos professores bolsistas para, depois, com eles, estendêla aos demais professores que trabalham com ensino de língua materna na rede.
} 
aproximando-nos ao que Wells (2006) compreende como tal: um espaço que envolve trabalho conjunto dos mais diferentes atores (pais, mães, professores, equipe diretiva, voluntários, comunidade, órgãos do governo) para criar melhores escolas para nossos alunos, ou seja, "todos pela educação". A comunidade de indagação é um grupo constituído de seis representantes da SMED - cinco professores e uma coordenadora pedagógica -, três doutorandos, uma mestranda, oito bolsistas de iniciação científica e duas pesquisadoras do PPGLA da Unisinos; e as comunidades de aprendizagem, hoje, consistem nas cinco turmas dos cinco professores mencionados anteriormente. Essas turmas, alocadas em cinco escolas distintas, apresentam realidades muito diversas: uma escola localizada em área rural; três escolas situadas na periferia do município, todas com indicadores baixos no Índice de Desenvolvimento da Educação Básica (IDEB), cada uma delas com problemas próprios - alunos provenientes de camadas populares, pais com baixa escolaridade, enfrentando problemas comuns a esses bairros: drogas, violência, e outros problemas sociais; e uma escola localizada na área industrial, com boa colocação no IDEB, pais de classe média, que estudaram na mesma escola e, por a avaliarem como boa, optaram por colocar seus filhos nessa instituição. Quatro desses grupos são de $6^{\circ}$ ano e uma de $8^{\circ}$. Todas as escolas receberam observações dos bolsistas de iniciação científica, que fizeram diários de campo e filmagens nos locais.

Quatro dos professores foram convidados pela SMED para participarem da pesquisa, e aceitaram o desafio. A coordenação de área de LP fez contato por e-mail com os professores da rede, apresentando o projeto aprovado pela Capes. Desses contatos, uma professora passou a integrar o grupo voluntariamente (sem saber que teria uma bolsa para o professor que participasse do projeto).

Essa comunidade de indagação se encontra regular e semanalmente. No início do ano, foi entregue o calendário do primeiro semestre, com a lista de textos, definidos pela equipe de pesquisadoras, a serem lidos e discutidos em seminários. A própria sala escolhida para esses seminários facilitou a interação entre os membros, sua cooperatividade. Todos os integrantes ficam dispostos em volta de uma grande mesa oval (palco das reunióes de colegiado do PPG), de forma que todos estão no mesmo plano, o que facilita a interação face a face. Foram doze encontros em que se discutiram textos sobre temáticas que o grupo de pesquisadoras julgava importantes discutir para formar uma base de conhecimento (concepções de linguagem; políticas públicas e concepções de ensino-aprendizagem de LP - PCN e Referenciais -; educação linguística; educação para a inclusão; letramento do professor/letramento do aluno; 
conceitos de leitura e produção de texto, com base em gêneros textuais/ discursivos; possibilidades de trabalho com gêneros na perspectiva de projetos), porque, do mesmo modo que Maria do Socorro Oliveira, acreditamos que "falta ao professor 'conhecimento reflexivo', pois somente a partir da consciência do que faz, ele pode ter controle sobre suas ações" (OLIVEIRA, 2008, p. 96). Depois, cada um desses cinco professores foi desafiado, a partir da sua realidade, a conceber um projeto para ser desenvolvido com seus alunos. A ideia é que cada um desses professores compartilhe com seus pares o que compreendeu na formação, na segunda etapa do Projeto, quando se passará a trabalhar com um professor de cada escola da rede municipal de Novo Hamburgo.

As comunidades de aprendizagem a que daremos destaque, como mencionamos, são cinco, das quais apresentaremos quatro, as formadas por cada um dos professores de $\sigma^{\mathrm{a}}$ série e seus alunos:

a) Escola 1: localizada em área rural do município de Novo Hamburgo, tem 217 alunos. As famílias vivem da agricultura, ou exercem atividades em uma pedreira (extração de pedra grés), ou como empregadas domésticas, diaristas, ou ainda trabalham na produção de hortaliças, pães, doces e compotas, hábitos que ainda permanecem da colonização alemã da região. As famílias participam bastante da vida da escola e, na maioria, ainda são constituídas de forma tradicional: pai e mãe casados, que vivem na mesma casa. A turma em questão tem 28 alunos - onze meninas e dezessete meninos.

b) Escola 2: localizada numa área periférica de Novo Hamburgo, tem 1.100 alunos. A turma em questão tem 22 alunos: quatorze meninas e oito meninos. A maior parte vive com os pais (dois dos alunos, órfãos de mãe, vivem com o pai). Os pais participam da vida escolar dos filhos somente quando são chamados pela escola, para entrega de boletins ou para falar sobre a rotina do aluno na escola. Apesar de contar com sala de informática e biblioteca, esses espaços não são usados no momento porque faltam o monitor e o bibliotecário. A escola tem um baixo índice no IDEB.

c) Escola 3: É uma escola tradicional, com quase cinquenta anos. Localizada na área industrial, tem 366 alunos. Os pais, de classe média e classe média baixa, são escolarizados (pelo menos primeiro grau completo); quatro deles têm ensino superior completo. Dedicam-se a diferentes atividades: merendeira, professora, funcionário público, motorista, autônomo, entre outras. Os alunos, no contraturno, têm aulas de natação, língua estrangeira, futebol, e ficam na companhia de parentes ou irmãos mais velhos. As famílias consomem jornais, revistas, leem notícias na internet, leem livros técnicos (apenas para 
o trabalho), dão livros de literatura para seus filhos - mesmo aqueles que não têm condiçōes acreditam que a leitura é necessária e acabam comprando livros de literatura mais baratos. Os alunos têm a prática de levar livros da biblioteca semanalmente e alguns pais também retiram livros. A turma em destaque tem 23 alunos: nove meninas e quatorze meninos.

d) Escola 4: Situada na periferia de Novo Hamburgo, a escola tem 1.100 alunos. As famílias são pobres, muitas em situação de risco social. Os pais que trabalham exercem atividades pouco remuneradas (como faxineiras, pedreiros) e já não têm uma constituição tradicional. Os alunos têm padrasto, algumas mães são separadas ou solteiras; alguns moram com avós. Há problemas sérios de assiduidade, muito em função da situação social. Existe também grande rotatividade de professores, muito possivelmente em função de condições adversas de trabalho. Apesar de a escola oferecer um amplo espaço e diferentes ambientes, falta conservação, pois o ambiente físico ainda precisa ser valorizado pelos próprios alunos. Além disso, está sem manutenção, e o prédio precisa de reparos. $\mathrm{O}$ trabalho foi desenvolvido em três turmas, abrangendo um total de 93 alunos.

\section{Começando a refletir sobre o projeto}

O projeto "Por uma formação continuada cooperativa: o processo de construção de objetos de ensino relacionados à leitura e produção textual" nasceu do trabalho de um grupo de pesquisa que sempre se preocupou com as questões de ensino-aprendizagem de LP com o docente dessa área e sua formação (GUIMARÃES [2004], [2005], [2006], [2007]; KERSCH; FRANK [2009]; KERSCH [2011]). Diversas dissertações do PPGLA encaminharam projetos nesse sentido (CAMPANI [2005]; DREY [2008]; REIS [2010]; DAGOSTIM PIRES [2009]; FRANTZ [2007]; PEREIRA [2008]; GARCIA [2009]; REIS [2010]; CARNIN [2011]). E esse grupo começou a se formar dentro de uma sala de aula de uma escola municipal de periferia da região metropolitana de Porto Alegre, quando desenvolveu, pela primeira vez, um trabalho baseado em gênero de texto. Na verdade, essa primeira experiência se deu com o gênero conto de fadas, numa proposta de sequência didática (SD), nos moldes que Schneuwly e Dolz (2004) propuseram. Essa e outras experiências deram origem ao livro Gêneros de texto no dia-a-dia do Ensino Fundamental.

Reflexôes sobre o trabalho com SD levou o grupo a questionar se não estava diante de um processo que corria sério risco de artificializar a noção de 
gênero, ao escolarizá-lo num modelo como o proposto pelas SDs. Além disso, a organização proposta pelo grupo de Genebra tem como fio condutor os chamados agrupamentos de gêneros (gêneros do narrar, do relatar, do argumentar, do expor e do descrever ações), o que deixava de lado duas questôes extremamente importantes para a sala de aula: o momento histórico - o que nos leva a escolher temas - e a própria constituição sócio-histórica de uma determinada escola e de seus aprendizes - o que nos leva às práticas sociais. Nesse ponto, os estudos de letramento nos auxiliaram na elaboração das propostas para os questionamentos que os professores trouxeram a partir de suas realidades de sala de aula:

a) Como tratar questōes de gênero, do tipo "diário é coisa de guria"?

b) Como explorar a questão da identidade negra, numa comunidade que tem dificuldade de aceitar o ser negro na escola e em que até na ficha de matrícula o preenchimento é orientado para a cor branca?

c) Como ajudar o aluno a entender melhor as propagandas veiculadas na mídia?

d) Como trabalhar uma narrativa de detetive, cheia de referências à Inglaterra da Scotland Yard e Sherlock Holmes, numa turma de Ga série em que muitos alunos tremem ao ouvir a palavra policial e a maior parte deles gosta de contar as tragédias do bairro, relacionadas à truculência de uma região metropolitana periférica?

Para tentar encontrar respostas a esses questionamentos, desenvolvemos a noção de projeto didático de gênero (PDG). Tendo um gênero de texto/ discurso como catalisador, abre-se a possibilidade de didatizá-lo, para, no sentido vygotskiano, os alunos se apropriarem de textos de determinada esfera da atividade humana. Falamos e escrevemos através de gêneros, portanto essa não é uma tarefa que acontece apenas na escola. A escola é uma das esferas sociais em que dado gênero circula (e, muitas vezes, de forma artificial). $\mathrm{O}$ desafio dos professores foi conectar o gênero a outras esferas em que o aluno possa circular, esferas mais ou menos formais, em que possa vir a usar o gênero de que se apropriou. Era necessário conectar também a escola à comunidade em que se acha inserida e às diferentes práticas sociais dessa comunidade, em que determinado gênero circula e, por essa razão, faria sentido para a vida do aluno. Vale lembrar que não se trata de ensinar um gênero pelo gênero, pelo conhecimento e/ou identificação de suas características composicionais, por exemplo, mas trata-se de ensinar a usar o gênero, apropriar-se dele para agir com eficiência em outras práticas sociais. 
A proposta é que o PDG represente uma co-construção de conhecimento para uma prática social que possa se inscrever em situações significativas para os aprendizes e para seus docentes. Esse projeto pode ser delineado a partir de diferentes entradas: um tema, uma prática social, um gênero mesmo do oral ou do escrito, um conteúdo gramatical. Estará necessariamente ligado a uma concepção que entende a linguagem como forma de interação, ou seja, como trabalho coletivo, social e historicamente situado e, por essa razão, orientado a uma finalidade específica, que se realiza nas práticas sociais existentes, nos diferentes grupos sociais de dada comunidade. Terá como características básicas: trabalhar a leitura (incluindo leitura do não verbal) numa situação dialógica, numa atitude responsiva ativa (como propõem Voloshinov e Bakhtin) e focar, no máximo, dois gêneros, numa relação clara com as práticas sociais da comunidade a que se destina. $\mathrm{O}$ projeto também se abre para a perspectiva interdisciplinar. Organizado em oficinas ou módulos, ocupará várias aulas, num trabalho sequencial, que incorporará toda a estrutura composicional do gênero trabalhado e vai se abrir para questões gramaticais que ajudem a produção do gênero em questão. Trabalhará, como afirmam Schneuwly e Dolz (2004), com a noção de que um gênero a ensinar também deve ser um gênero a comunicar. Uma produção inicial pode ser um passo importante para conhecer o que os alunos já entendem do gênero e virá a se constituir em parâmetro de avaliação no cotejo com a produção final. Para avaliar os textos produzidos pelos alunos, será concebida, com eles, uma grade de avaliação, com critérios co-construídos em sala de aula. A opção pelo gênero a ser trabalhado levará em conta a realidade dos alunos, o seu pertencimento a determinado grupo social como ponto de partida. Além disso, o foco do professor fica na pergunta "por que ensino o que ensino a estes alunos?".

Ler e escrever são atividades extremamente complexas, inseparáveis das pessoas e do local em que elas estão, da cultura em que se acham inseridas. Falar de leitura e escrita na escola implica falar daquela comunidade de aprendizagem (WELLS, 2006), do que significa ler e escrever aquele texto para aquele grupo. Pensar um PDG é situá-lo social e historicamente, o que requer que o professor (ou o agente que vai desenvolvê-lo) ao pensar o letramento dos alunos, desenvolva um senso de lugar, de comunidade, o que o leva a olhar para seus alunos e para o entorno, identificando os letramentos e as práticas comuns ali (ou ainda passíveis de serem desenvolvidas), enfim, os gêneros necessários para aquelas práticas. E é disso que tratam os quatro projetos, que emergiram das perguntas que os professores trouxeram para o grupo. 
a) PDG com diário: numa comunidade de características rurais, onde nem sempre o celular pega (Escola 1), a professora percebeu que os alunos têm uma convivência muito próxima entre si, familiares e vizinhos: nos finais de semana, dormem nas casas uns dos outros para brincar, vão passear na casa dos avós. Essas características a fizeram trabalhar com o gênero diário ${ }^{6} \mathrm{e}$ discutir questôes de gênero com eles.

b) PDG com ladainha de capoeira: articulando História, Artes e LP (Escola 3), a professora decidiu trabalhar esse gênero porque viu a necessidade de construir o conhecimento e a compreensão sobre a história afro-brasileira, bem como valorizar a própria história dos alunos através do gênero oral ladainha, fazendo com que os alunos negros da turma se orgulhassem de suas origens, reconstruindo sua identidade de afro-descendente.

c) PDG com fôlder: ao descobrir que os alunos assistiam muito à televisão e viam muitos comerciais, o professor (Escola 2) resolveu analisar alguns comerciais, o que levou o grupo a trabalhar com o fôlder, relacionando-o ao tema da alimentação saudável, desenvolvido em articulação com Ciências.

d) PDG com narrativa de detetive: o gosto dos alunos de contar tragédias ocorridas no bairro, as ameaças de que "vais acabar no valão com a boca cheia de formigas", aliados ao medo de alguns alunos da polícia (Escola 4) fez com que a professora decidisse, a partir da ficção, auxiliar os aprendizes a construir novo entendimento da sua realidade.

Esses projetos, desenvolvidos a partir das práticas comuns ou recorrentes que cada professor identificou, favoreceram a oferta de eventos de letramento que privilegiassem determinado gênero. ${ }^{7}$

E qual a relação entre os estudos de letramento e a sala de aula de LP? Eles impactam a educação na medida em que o elemento estruturante do currículo do ensino é a prática social e não mais o construto formal teórico. A prática educativa, nessa perspectiva, está a serviço de um ensino que tem como ponto de partida o conhecimento de mundo do educando e não uma lista de conteúdos a serem vencidos (como se os conteúdos fossem inimigos

${ }^{6}$ Iniciou com $O$ diário de um banana, de Jeff Kinney, editora Vergara \& Riba.

${ }^{7}$ As práticas são entendidas aqui como formas culturais de letramento (BARTON; HAMILTON, 1998) e são mais abstratas e não observáveis; já os eventos são as atividades (observáveis) que emergem das práticas e que têm a leitura e escrita como base; é nos eventos que as práticas são postas em ação. Essa noção de evento dá destaque ao caráter situado do letramento, que sempre ocorre num contexto social. 
do professor). A escola passa a ter de se reconhecer dentro de uma comunidade, em que tem o papel de reconhecer a existência desses outros letramentos, e de preparar o aluno para agir na sociedade em que vive, para, com autonomia, participar das inúmeras práticas sociais de sua cultura, cujo ponto de partida são a leitura e a escrita. É tarefa da escola promover atividades várias que abarquem o universo de linguagens que nos cercam, tanto dentro quanto fora dela.

O conceito de letramento visto como algo bem mais amplo que a alfabetização, porque se preocupa com a forma como os indivíduos se apropriam da tecnologia da leitura e da escrita, de como agem em contextos em que a leitura e a escrita são requeridas, abre espaço para uma nova forma de conceber o ensino de língua, que tem de ser visto também ele situado social e historicamente, e não descontextualizado e desconectado do que acontece na comunidade. Ao oferecer eventos que envolvem a escrita, inserindo os alunos nas práticas letradas da sociedade, identificando os gêneros que circulam naquelas práticas, a escola estará levando-os a se comunicarem por escrito numa gama variada de situações (e possivelmente com mais competência, pelo menos esse é seu papel).

Acreditamos que, no momento em que se oferece aos alunos a possibilidade de organizar os saberes da comunidade, eles terão uma nova visão da realidade que os cerca. Novas identidades serão construídas, porque um novo olhar será lançado sobre a comunidade e o entorno, o que pode levar os alunos a ter outra consciência sobre si e sobre os outros. Escrevendo para um fim específico, os alunos estarão motivados a fazer aquilo que não é imediatamente aplicável, mas socialmente relevante e, por isso, vale a pena ser aprendido.

Um PDG da forma como o pensamos com nossos professores colaboradores promove um ambiente em que o aluno tem contato com o texto em situações reais. Se é tarefa da escola contribuir para a formação de cidadãos mais autônomos e mais críticos, isso pode se dar ao promover a leitura de textos que, de fato, circulam na sociedade, e ao oportunizar a produção de textos que realmente serão lidos - e não apenas escritos para serem avaliados pela professora.

\section{Fechando o primeiro ciclo do projeto}

Trazer um aspecto da vida da comunidade para a sala de aula, avaliar o que se faz, e se submeter à avaliação da comunidade de indagação não é tarefa fácil. É preciso desconstruir mitos e crenças, é preciso que os professores colaboradores realmente percebam também os pesquisadores como tal. A 
resposta aos questionamentos trazidos ao grupo não sai necessariamente dos pesquisadores. Essa é sempre discutida em conjunto. Todos do grupo, desde bolsistas de iniciação científica a professores e doutorandos, são estimulados a também eles terem uma atitude responsiva ativa em relação aos textos que sustentam a nossa proposta e em relação às ideias que circulam no grupo.

Estamos todos inseridos em diferentes práticas sociais e, numa sociedade letrada como a nossa, grande parte delas se organizam a partir de um texto escrito; são, pois, práticas de letramento. Para que os professores pudessem se dar conta dessa "rede de práticas" em que cada cidadão se acha enredado, criamos o espaço para isso: a comunidade de indagação - com encontros semanais, em que se investe na formação continuada dos professores, discutindo temas abordados pela ciência linguística e sancionados pelos documentos oficiais (concepções de linguagem, letramento, gêneros textuais, por exemplo). Como pesquisadoras, temos a convicção de que a mudança se dá quando é dada voz ao professor (para que ele, posteriormente, possa dar voz aos seus alunos).

O professor que aceita o desafio de trabalhar de forma colaborativa numa pesquisa liderada por pesquisadores ligados a um Programa de PósGraduação é um profissional que quer fazer a diferença no seu local de trabalho, que se sente desafiado a inovar a sua prática. Entretanto, a maioria deles se encontra entre a cultura do tradicional, por meio da qual se deu toda a sua formação (os anos na universidade, na maioria dos casos, não são suficientes para desconstruir antigas convicções), e a cultura da tecnologia e de diferentes mídias, presente nas demandas da sociedade contemporânea. Nesse contexto, além dos conceitos de que precisa se apropriar, há mitos e crenças que precisam ser desconstruídos e, em decorrência, novas identidades são construídas. E os projetos - entendidos como práticas sociais -, no nosso entender, se prestam para dar conta de toda essa complexidade envolvida na formação continuada de professores e, por extensão, na ressignificação das práticas de leitura e escrita na escola.

Ao colocarmos tanto o gênero quanto a temática do(s) letramentos como protagonistas, num mesmo plano, esperamos estar lançando um novo olhar para o ensino de LP em nossas escolas. E, ao alimentar nossa teoria com a prática e com a voz dos professores, co-construindo conceitos, passamos, enquanto pesquisadoras, a nos compreender de outra forma. Nessa rede complexa, alunos, professores e pesquisadoras firmam, reafirmam, contrapõem e desmentem sentidos, num movimento dialógico e contínuo. 
Acreditamos que, para que os resultados da pesquisa linguística cheguem à sala de aula, a academia precisa ver no professor um colaborador (e também ele precisa ver seus alunos e o pesquisador como parceiros, aliados; e, no caso desse último, não como um avaliador), interessados que todos estamos em que nossas crianças e jovens recebam uma educação linguística de qualidade. $\mathrm{O}$ espaço da comunidade de indagação está sendo fundamental para criar com esses professores uma cultura de reflexão e análise das práticas realizadas, a fim de que eles (e nós) possam transformar suas ações e as práticas escolares a partir do que discutimos juntos. E depois auxiliem seus pares na mesma reflexão, num caminho de crescimento dessa comunidade. ${ }^{8}$

Assim como o PDG representa uma co-construção de conhecimento para uma prática social que possa se inscrever em situaçôes significativas para os aprendizes, o processo de formação continuada de professores, no "trabalho de formiga" proposto, também só pode ser entendido como uma coconstrução, como uma inter-relação de saberes: os experienciais/práticos e os acadêmicos. Esperamos ouvir, então, o comentário que iniciou este artigo reformulado para algo como: "Lá da Uni vão vir ajudar no meu trabalho e dizer que vale a pena".

\section{Referências}

ANTUNES, I. Lingua, texto e ensino: uma outra escola possível. São Paulo: Parábola, 2009.

BAKHTIN, M. Estética da criação verbal. 4. ed. São Paulo: Martins Fontes, 2003. BAKHTIN, M.; VOLOSHINOV, V. Marxismo e filosofia da linguagem. 13. ed. São Paulo: Hucitec, 2006.

BARTON, D.; HAMILTON, M. Local Literacies: Reading and Writing in One Community. New York: Routledge, 1998.

BRASIL. Ministério da Educação e Cultura. Secretaria da Educação Básica. Parâmetros curriculares nacionais: língua portuguesa. 3. ed. Brasília: Secretaria da Educação Básica, 1998.

${ }^{8}$ Como já dissemos, estamos na primeira etapa do projeto. A próxima etapa, iniciada em agosto de 2011, envolve cinquenta professores de LP da rede municipal, num crescimento escalonado da proposta. A etapa subsequente trabalhará com o restante dos professores da rede, sem deixar de acompanhar esses cinquenta docentes, que passarão, então, à comunidade de indagação. 
BRONCKART, J. P. Commentaires conclusifs: pour un développement collectif de l'interacionnisme socio-discursif. Calidoscópio, São Leopoldo, v. 2, n. 2, p. 113-123, jul.-dez. 2004.

BUNZEN, C. Da era da composição à era dos gêneros: o ensino de produção de texto no Ensino Médio. In: BUNZEN, C.; MENDONÇA, M. (Org.). Português no Ensino Médio e formação do professor. São Paulo: Parábola Editorial, 2006. p. 137-161.

CAMPANI, D. Questôes para além da didatização do gênero: um olhar para o ensino de pontuação em sequência didática sobre o gênero textual conto humorístico infantil. 2005. 220 f. Dissertação (Mestrado em Linguística Aplicada) - Programa de Pós-Graduação em Linguística Aplicada, Universidade do Vale do Rio dos Sinos, São Leopoldo, 2005.

CARNIN, A. Entre a formação inicial de professores de lingua portuguesa e o trabalho real: a (co)construção do objeto de ensino produção textual escrita. 2005. Dissertação (Mestrado em Linguística Aplicada) - Programa de Pós-Graduação em Linguística Aplicada, Universidade do Vale do Rio dos Sinos, São Leopoldo, 2011.

DAGOSTIM, P. V. Andamento coletivo como prática de ensino-aprendizagem de Lingua Portuguesa para surdos. 2009. Dissertação (Mestrado em Linguística Aplicada) - Programa de Pós-Graduação em Linguística Aplicada, Universidade do Vale do Rio dos Sinos, São Leopoldo, 2009.

DOLZ, J. Los cinco grandes retos de la formación del profesorado de lenguas. In: SIMPÓSIO INTERNACIONAL DE ESTUDOS DE GÊNEROS TEXTUAIS - SIGET, 5., 2009, Caxias do Sul. Anais... Caxias do Sul: UCS, 2009.

DONATO, R. Collective Scaffolding in Second Language Learning. In: LANTOLF, J. P.; APPEL, G. (Org.). Vygotskian Approaches to Second Language Research. New Jersey: Norwood, 1994.

DREY, R. F. Eu nunca me vi assim de fora: Representaçôes sobre o agir docente através da autoconfrontação. 2008. 162 f. Dissertação (Mestrado em Linguística Aplicada) - Programa de Pós-Graduação em Linguística Aplicada, Universidade do Vale do Rio dos Sinos, São Leopoldo, 2008.

FRANCHI, C. Criatividade e gramática. Trabalhos em linguística aplicada, Campinas: Unicamp; IEL, n. 9. p. 5-45, 1987.

FRANTZ, C. S. Ação e reflexão docente: contribuições para os processos de ensino e de aprendizagem da língua escrita no contexto de uma turma de progressão. 2007. Dissertação (Mestrado em Linguística Aplicada) - Programa de PósGraduação em Linguística Aplicada, Universidade do Vale do Rio dos Sinos, São Leopoldo, 2007. 
GARCIA, R. S. O que dizem pareceres descritivos de alunos de séries iniciais do ensino fundamental sobre a aprendizagem da lingua materna?. 2009. 130 f. Dissertação (Mestrado em Linguística Aplicada) - Programa de Pós-Graduação em Linguística Aplicada, Universidade do Vale do Rio dos Sinos, 2009.

GUIMARÃES, A. M. de M. A interpretação de texto: um olhar pedagógico na perspectiva de formação de um leitor ativo e crítico. In: SENALE, 6., 2010, Pelotas. Anais... Pelotas: UCPEL, 2010.

GUIMARÃES, A. M. de M.; CAMPANI-CASTILHOS, D.; DREY, R. Gêneros de texto no dia-a-dia do Ensino Fundamental. Campinas: Mercado de Letras, 2008. GUIMARÃES, A. M. de M. Construindo propostas de didatização de gênero: desafios e possibilidades. Linguagem em (Dis)curso, Tubarão, v. 6, n. 3, set.-dez. 2006.

GUIMARĀES, A. M. de M. Desenvolvimento de narrativas e o processo de construção social da escrita. Calidoscópio, São Leopoldo, v. 2, n. 2, p. 67-74, dez. 2004.

GUIMARÃES, A. M. de M. O agir educacional nas representações de professores de língua materna. In: GUIMARÃES, A. M. de M.; MACHADO, A. R.; COUTINHO, A. (Org.). O interacionismo sociodiscursivo: questóes epistemológicas e metodológicas. 1. ed. Campinas: Mercado de Letras, 2007. v. 1, p. 201-219. GUIMARÃES, A. M. de M. Reflexões sobre didatização de gênero. Signum, Londrina, v. 6, n. 1, p. 71-88, 2005.

KERSCH, D. F. Eles sempre vão lembrar disso: quando a cultura do aluno vira assunto da aula de língua portuguesa. Desenredo, Passo Fundo, v. 7, n. 1, p. 3251, jan.-jun. 2011.

KERSCH, D. F.; FRANK, I. Aula de Português: percepções de alunos e professores. Calidoscópio, São Leopoldo, v. 7, p. 46-58, 2009.

KLEIMAN, A. B. (Org.). Os significados do letramento: uma nova perspectiva sobre a prática social da escrita. Campinas: Mercado de Letras. (Letramento, Educação e Sociedade).

KLEIMAN, A. B. Letramento e suas implicações para o ensino de língua materna. Signo, Santa Cruz do Sul, v. 32, n. 53, p. 1-25, 2007.

KLEIMAN, A. B. O processo de aculturação pela escrita: ensino da forma ou aprendizagem da função? In: ; SIGNORINI, I. (Org.). O ensino e a formação do professor: Alfabetização de jovens e adultos. Porto Alegre: Artmed, 2000. p. 223-243.

KLEIMAN, A. B. Os estudos de letramento e a formação do professor de língua materna. Linguagem em (Dis)curso, Tubarão, v. 8, n. 3, p. 519-541, 2008. 
KLEIMAN, A. B. Preciso "ensinar" o letramento? Não basta ensinar a ler e escrever? Campinas: Cefiel - Unicamp; MEC, 2005.

OLIVEIRA, M. do S. Gêneros textuais e letramento. Revista Brasileira de Linguística Aplicada, Belo Horizonte, v. 10, n. 2, p. 325-345, 2010.

OLIVEIRA, M. do S. Projetos: uma prática de letramento no cotidiano do professor de língua materna. In: KLEIMAN, A. B.; OLIVEIRA, M. do S. (Org.). Letramentos múltiplos: agentes, práticas, representações. Natal: EDUFRN, 2008. p. 93-118.

PEREIRA, M. C. P. Testes de proficiência linguistica em lingua de sinais: as possibilidades para os intérpretes de Libras. 2008. Dissertação (Mestrado em Linguística Aplicada) - Programa de Pós-Graduação em Linguística Aplicada, Universidade do Vale do Rio dos Sinos, São Leopoldo, 2008.

REIS, T. H. A rádio papagaio está no ar: uma experiência com gêneros orais na escola. 2010. Dissertação (Mestrado em Linguística Aplicada) - Programa de Pós-Graduação em Linguística Aplicada, Universidade do Vale do Rio dos Sinos, São Leopoldo, 2010.

RIO GRANDE DO SUL. Secretaria de Estado da Educação. Referenciais Curriculares do Estado do Rio Grande do Sul: Linguagens, códigos e suas tecnologias. Porto Alegre: SE/DP, 2009.

ROJO, R. Letramentos múltiplos, escola e inclusão social. São Paulo: Parábola Editorial, 2009.

SCHNEUWLY, B.; DOLZ, J. Gêneros orais e escritos na escola. Tradução e organização de Roxane Rojo e Glaís Sales Cordeiro. Mercado de Letras, 2004.

SCHNEUWLY, B.; DOLZ, J. Os gêneros escolares: das práticas de linguagem aos objetos de ensino. In: . Gêneros orais e escritos na escola. Tradução e organização de Roxane Rojo e Glaís Sales Cordeiro. Mercado de Letras, 2004. p. 71-94.

SOARES, M. Novas práticas de leitura e escrita: letramento na cibercultura. Educação \& Sociedade, Campinas, v. 23, n. 81, p. 143-160, dez. 2002. Disponível em: <http://www.scielo.br/scielo.php?script=sci_arttext\&pid= S0101-73302002008100008\&lng=en\&nrm=iso >. Acesso em: 30 jun. 2011.

STREET, B. Literacy in Theory and Practice. Cambridge (MA): Cambridge University Press, 1984.

TINOCO, G. A. Usos sociais da escrita + projetos de letramento = ressignificação do ensino. In: GONÇALVES, A. V.; BAZARIM, M. (Org.). Interação, gêneros e letramento: a (re)escrita em foco. São Carlos: Claraluz, 2009.

VYGOTSKY, L. S. Pensamento e linguagem. São Paulo: Martins Fontes, 1989. 
WELLS, G. Dialogic Inquiry as Collaborative Action Research. Handbook of Educational Action Research. SOMEKH, B.; NOFFKE, S. (Ed.). 2007. Disponível em: <http://people.ucsc.edu/_gwells/Files/Papers_Folder/ Collaborative\%20Action\%20Research.pdf>. Acesso em: 22 ago. 2009.

WELLS, G. La unión de las dimensiones sociales, intelectuales y afectivas de la educación para transformar la sociedad. In: ALCALDE, A. I. et al. Transformando la escuela: las comunidades de aprendizaje. Barcelona: Editorial Grao, 2006. p. 19-28. 